\title{
Somatic Practices - how motion analysis and mind images work hand in hand in dance
}

\author{
Sarah Whatley \\ Coventry University \\ s.whatley@coventry.ac.uk \\ 07974984304
}

\begin{abstract}
Somatic Practices are body-based movement practices that foreground self-awareness and a first person experience of moving. Increasingly, somatic practices are informing how dance is taught, created and performed with many dancers turning towards somatics to ensure a healthy and holistic approach to dance. Several somatic practices draw on imagery as a source for moving, for stimulating a more sensorial engagement with movement and to encourage a sense of moving 'naturally' and with respect for the 'natural environment'. When somatic practices and the imagery that is important for many of these practices are coupled with motion analysis tools, the necessary processing of movement often requires an intervention that can disrupt the 'natural' sense of moving somatically. This processing can thus appear to be at odds with a somatic approach to dance. However, there are many examples where motion analysis and mind images do work hand in hand in dance, and can generate exciting new insights to the production, teaching and making of dance. It is this intersection between somatic principles, imagery and motion analysis tools that is the focus for this essay, which discusses projects that have explored and exploited the intersection between motion analysis, imagery and somatic practices.
\end{abstract}

\section{Key words:}

Dance, somatic practices, imagery, Motion Capture, WhoLoDance, Ruth Gibson, hologram

\section{Introduction}

Somatic practices are body-based movement practices that foreground self-awareness and a first person experience of moving. Increasingly, somatic practices are informing how dance is taught, created and performed with many dancers turning towards somatics to ensure a healthy and holistic approach to dance. Several somatic practices draw on imagery as a source for moving, for stimulating a more sensorial engagement with movement and to encourage a sense of moving 'naturally' and with respect for the 'natural environment'. When somatic practices and the imagery that is important for many of these practices are coupled with motion analysis tools, an interesting friction arises that might seem to intervene in the premise on which somatic practices rely. This is because the introduction of technology that requires the processing of movement often requires an intervention that can disrupt the 'natural' sense of moving somatically, whether for analyzing the biomechanical properties of movement or to generate visualisations for aesthetic purposes. This processing can thus appear to be at odds with a somatic approach to dance. However, there are many examples where motion analysis and mind images do work hand in hand in dance, and can generate exciting new insights to the production, teaching and making of dance. It is this intersection between somatic principles, imagery and motion analysis tools that is the focus for this essay. Beginning with an overview of somatic practices and their influence on dance more generally, the discussion will then examine the role of imagery in dance and how imagery has played a role in motion analysis, with specific reference to motion capture. Reference will be made to two projects that have explored and exploited the intersection between motion analysis, imagery and 
somatic practices, and which have contributed to revealing more about the subtleties and the 'hidden' complexities of dance.

\section{State of the Art}

For many years, dance and somatic-informed dance practices have been a source for experts who are interested in the complexity of human motion and expression. But dance is also a broad category and takes on myriad roles; as art form, a traditional cultural practice, a route to enhanced health and well-being, or as a recreational activity. There have been many projects that have brought together experts to explore the use of new technological tools for multimodal analysis of dance movement for different purposes including the teaching of dance, for biomechanical purposes as well as for performance creation. Different areas of dance have been covered by a number of projects and many have focused in particular on Motion Capture, Dance Notation and Animation. For example, Antonio Camurri has developed a 4-layer conceptual model of automated analysis of dance (2003), as well as modules for real time analysis of movement and mapping, and an interactive sonification component to transform a movement quality in the auditory domain (2005). Starting from low-level physical measures of the video-tracked whole-body silhouette, Camurri et al identified motion features, such as the overall amount of motion computed with silhouette motion images, the degree of contraction and expansion of the body, or the motion fluency computed on the basis of the changes of the overall amount of motion over time. On the basis of these motion features, they were able to distinguish between four emotional performances of a dance sequence (anger, fear, grief, and joy) by four dancers. This framework of visionbased bodily expression analysis was used for a number of multimodal interactive applications, in particular in performing arts and mainly include support vector machine techniques for real-time affective classification (2005, 2007). Kapur et al (2005) used fullbody skeletal movement data (obtained with the VICON motion capture system on five participants) to distinguish automatically between the same four basic emotional states, and Camurri et al developed a qualitative approach to human full-body movement for affect recognition (2003).

Motek Entertainment ${ }^{1}$ and its sister company Motek Medical have developed several inhouse tools for real-time blending of motion capture data. Motek have also been active in the last decade in progressing the building of systems with multimodal input and output capabilities. Similarly, from a technological standpoint, holographic displays are becoming faster and less expensive to produce and research on electronic holography has yielded systems which provide full colour, moving holographic images. These developments have the potential to support the teaching and learning of dance, as will be discussed later. Other projects have worked on motion capture systems to support the teaching of dance. For example, Chan et al (2011) have described a new dance training system that they have developed based on motion capture and virtual reality technologies that can evaluate the difference between the learner and the virtual teacher. Their system claims to be able to carry out "a more comprehensive analysis of the user's whole body motion in order to let him/her know, which body parts are moved incorrectly" $(2011,187)$ and can provide feedback by comparing two motions, producing, they assert, a fun and motivating learning experience.

The motion analysis of dance for biomechanical purposes has also spawned interest in motion capture for other physical activities. For example, James Shippen's work in using a VICON motion capture lab for creating a software based on engineering principles to analyse the movement of the human body, and analyse how it reacts to different loads and postures, was initially developed to examine the effect on dance on the musculoskeletal system for

\footnotetext{
${ }^{1}$ See http://www.motekentertainment.com/
} 
injury prevention. With a focus on Irish dancers, using an optical tracking system and floor mounted forceplates, Shippen researched the kinematics, kinetics and internal muscle loadings in order to improve performance and reduce the risk of injuries (Shippen and May 2010). Working with the dancers and their teachers Shippen noted the importance of imagery in the dancers' rehearsal process and created a colour coded graphics for visualisation of individual muscle activity and tabulated muscle loading data for easy interpretation of the results. More recently he transferred this knowledge to examining the physical aspects of the most common horticultural activities, using the Xsens motion capture system (Shippen et al 2015).

A very different project is Motion Bank ${ }^{2}$, which has developed a range of computer-aided visualisations of dance, and the structures that underpin dance works, for arts education and interdisciplinary research. The project brought together researchers, leading dance choreographers, designers, educators and computer scientists. The aim was to "explore how digital technology can be uniquely applied to the challenge of documenting, analysing, notating/annotating and presenting dance" $(2011,12)$ by archiving a number of choreographers' conceptual approaches along with video recordings and three-dimensional data documenting the performances and the depictions created by the designers. Incorporating different motion analysis tools including Kinect and Motionbuilder to visualize different aspects of the choreographer's work, a number of digital scores have been created as a result of this interdisciplinary design process.

A leading expert in motion analysis and motion capture technology, Kim Vincs, based at Motion.lab Deakin, Australia, has conducted a number of projects that have contributed to furthering knowledge about the affordances of motion analysis for dance research and practice. In a recent project (2014), Vincs and Barbour employ principal component analysis (PCA) techniques in conjunction with motion capture to uncover more about variability and consistency within and across different dance practices. Their findings are very interesting for a number of reasons. First, they advise careful consideration in using PCA because as "dance can potentially communicate across both high and low level features, analysis that focuses solely on high-level features to minimise computational complexity and optimise recognition risks eliminating key artistically and culturally valent aspects of the movement" $(2014,65)$. They then argue that their data suggests that the organization of dance into different practices "operate more cohesively on a conceptual level than it does at the microlevel of movement patterning made visible by PCA analysis" $(2014,75)$ challenging "our culturo-aesthetic assumptions about how certain kinds of dance are produced" $(2014,75)$. Their research has thus contributed to thinking about the place of different statistical analyses in the analysis of dance, suggesting that it is "not only larger, locomotor movement that elicits more variable movement patterning" $(2014,74)$ and by extension, variability might therefore be an aesthetic choice (made by the dancer) as well as a biomechanical one $(2014,74)$.

\section{Somatic practices in context}

Somatic practices have a long lineage. Beginning as far back as the late nineteenth and twentieth centuries in Europe and America, somatics can be seen to have its roots in the work of Francois Delsarte, an actor and opera singer (1811-71), who created a system in the mid nineteenth century based on his observations of human interaction that aimed to connect the inner emotional experience with a systematized set of gestures, speech and movements. His work had a significant influence on modern dance as it was emerging, including the early days of somatics. Many of the underlying theories that have informed somatic systems originated in Germany around that time - movement teachers Elsa Gindler, Heinrich

\footnotetext{
${ }^{2}$ See Motion Bank website: http://motionbank.org/
} 
Gimmler, Bess Mensendieck, Ilse Middendorf and Marion Rosen were all important in constructing the foundation for somatic work.

Almost a century later and in 1976 Thomas Hanna, a US practitioner and philosopher, named the field Somatics (1980), recognising a number of embodied disciplines that collectively share a focus on sensory awareness. Contemporary practices that are generally regarded as promoting somatic principles include Alexander Technique, the Feldenkrais Method ${ }^{\circledR}$ and particularly Feldenkrais' Awareness Through Movement method, Body Mind Centering $®$, Skinner Releasing Technique ${ }^{\mathrm{TM}}$, and Authentic Movement, amongst others, all with their own innovators and legacy of teachers. As examples of reflection-in-action, these techniques facilitate self-awareness and engage with what Michel Foucault termed 'Technologies of the Self' (1988). Many are intended to be used 'by the self on the self' and maintain the goal of educating attentional skills. Some of these contemporary somatic practices have been influenced by eastern philosophy and body practices including yoga, martial arts, Shiatsu, Chi Kung and Buddhist meditation. Along with Kinesiology education, they support a principle of developing mind through body, so that the training of one creates knowledge within the other ${ }^{3}$.

Somatics are thus variously described as centred in first-person sensory and body-based techniques, experiences and methodologies, and self-reflexive techniques structured to transform one's experience of the self in the world. They promote the unity of mind and body, and the body as contextual and fluid. They give rise to theories of embodiment ${ }^{4}$ and encourage verbalization, questions and comments. Participants are encouraged to speak from their movement explorations, to develop a consciousness of their bodily practices and an awareness of their movement patterns (Harbonnier-Topin and Simard 2015). The appeal of the body-based practices of somatics to dancers has grown through a long and interconnected history, resulting in a close relationship, particularly with contemporary dance techniques.

Many dancers and somatic movement practitioners will consider themselves philosophers as much as movers. Recent writings (Fraleigh 2015, Williamson 2016) have demonstrated not only how established philosophy (particularly phenomenology) has inspired and informed somatic movement practices, but the moving, thinking and writing contributes to a somatic philosophy that forms its own particular way of being and moving in the world. Hence it may be useful to think of somatic work as a philosophy rather than as a philosophy of somatic practices. Many dancer scholars draw substantially on philosophical frameworks and particularly phenomenology, and the philosophers most closely aligned with its origins, Edmund Husserl (1859 - 1938) and Merleau-Ponty (1908 - 1961). Phenomenology promotes the belief that meaning comes from our experiences of phenomena, fosters the idea that consciousness is based in the lived body, and emphasizes the importance of bodily knowledge. And as philosopher Manen argues, as a methodology, phenomenology looks at how a thick description of lived experience helps us explicate meanings as we live them (1990). By arguing for the body as a primary source of knowing, for intersubjectivity (an intimate connection between subjectivity and the subject) and shared experience, it has been widely drawn upon by somatic dance practitioners/philosophers, notably Maxine SheetsJohnstone (1980), Sondra Fraleigh (1996, 2015), Williamson (2010) and Kozel (2008).

Other theorists that have informed those working in somatics include the American philosopher and educationalist John Dewey (1859-1952) who studied with Matthias

\footnotetext{
${ }^{3}$ For a valuable and extended account of the history of somatic practices as they have developed and in particular formed a relationship with HCI in thought and practice, see Thecla Schiphorst's PhD thesis: http://www.sfu.ca/ tschipho/PhD/PhD thesis.html. ${ }^{4}$ There are many and varied theories of embodiment; in broad terms embodiment refers to how our bodies and active experiences shape how we think, feel and perceive.
} 
Alexander for more than 20 years in the early part of the $20^{\text {th }}$ century and was influenced by his teachings, particularly those that informed his educational theory relating to self-agency and ethics. Dewey's reference to 'body-mind' as an essential unity, based on his argument that mind emerges from body's more basic physical and psycho-physical functions, rejected the idea that mind and cognition are superimposed on the soma by transcendent powers of reason emanating from a spiritual world beyond nature (1958). A contemporary philosopher of aesthetics, Richard Schusterman has also influenced somatics with his argument that the body is our basic medium of perception and action by drawing on insights from body-mind awareness and the aesthetic dimensions of everyday life (2008). He is perhaps best known for his development of the field of somaesthetics (1999) through an integration of the disciplines of philosophy of mind, ethics, politics, social theory, gender studies and aesthetics. These and other theories have fuelled a broader somatic turn within dance, movement and therapeutic practices and a range of somatic modalities are now practiced widely within dance teaching and training.

A focus on psycho-social-somatic learning gives rise to what could thus be termed a corporeal philosophy; a philosophy that attends to the lived body, promoting both an inward and outward focus that relates to context, condition, experience, cultural connections, ethics and ecological factors. Dance scientist Glenna Batson has argued for the importance of attention in dance practice, claiming that attending to bodily sensations is essential to coordinating mind and body, and is fundamental to the capacity and capability of building relationships to self and others (Batson, 2014, 106). Attending to sensory data coming from interior states, movement and environment provides a bridge between inner states and the outer world - expressing being and becoming in the world, of coupling thinking with worldmaking (Batson, 2014, 108). Attention is thus a basic somatic function and tuning attention is a core part of a dancer's practice.

\section{Imagery and dance}

Related to attention is imagery, which is often part of the dancer's toolkit, to prompt new movement creation, to notice movement 'habits' and to observe changes in perceptual focus. Batson notes how image can operate for dancers:

First, an image can arise intuitively simply from exploring movement; second, images can shape and alter the dynamics of an ongoing movement; and third, images can allow the dancer to project outside of self, offering ways to observe the self in interacting with space, time and others.

(Batson 2014, 61)

Imagery is used regularly in the teaching of dance and has a long history. Several texts have focused on the way image supports the biomechanical principles of dance movement and the role of imagery in a dancer's understanding of anatomical structure and function (Todd 1968, Sweigard 1974, Franklin 1996). Several dancers have since developed their own methods and movement systems, which are now very widely practiced. These include Joan Skinner, who was a pupil of dance teacher Cora Belle Hunter, who was herself a student of Todd. Skinner is one of several who have evolved her own method, in her case Skinner Releasing Technique ${ }^{\mathrm{TM}}$ (SRT) using guided poetic imagery, which she describes as 'image clusters' that are core to her work (cited in Neuhaus 2010).

Imagery may be visual, auditory (sonic) or kinaesthetic. How imagery enters the dance studio and rehearsal space varies according to the dance practice, technique or choreographic process. For example, whilst in a contemporary dance class the teacher may focus on one part of the body, providing anatomical information, advice about spatial factors, what body parts to move, as well as appropriate images to encourage different qualities of action and to 
engage the 'internal' physiological processes in moving from stillness to action. As the dancer moves in response, further spatial and dynamic instruction may be offered as well as imagery, which might be kinaesthetic, metaphorical or biomechanical. As the dancer continues to practice, the action may form itself into repeatable sequences. The dancer responds through conscious embodiment, combining awareness of imagery, anatomical and mechanical structures and constraints, and physiological processes, learning to manipulate abstract forms of kinaesthetic imagery.

Studies on imagery in dance have also been conducted by cognitive and behavioural scientists (McCarthy et al 2006, May et al 2011) who have uncovered the ways in which dancers are particularly expert in drawing on and sourcing imagery and move with ease between different sense modalities. For example, the studies conducted by a team of psychologists led by Jon May and working in collaboration with Wayne McGregor|Random Dance in the UK set out to "record dancers' awareness of their use of forms of imagery during movement creation, and to relate these measures to evidence of patterns of brain activity from neuroimaging studies" (May et al 2011, 405; italics in original). Their work showed how novel movement creation can start from both mental and physical processes. In dance practices that emphasise somatic principles, dancers often attune to imagery for the transformative potential of the image in their dancing. So for example, an image of a feather floating to the floor might initiate movement that is light in quality and free flowing in space. The image is internalized and encourages personal autonomy in the dancer whilst promoting sensory awareness and the tuning of the body to the environment and other dancers. The image thus enables the dancer "to experience a personalized version of them so they are relevant to each individual's process and needs as they are situated in that precise moment in time" (Emslie 2009, 173). In these cases, the image is a mental image, offered to the dancer to motivate movement.

\section{Mind images and motion analysis}

The role of mind images in dance when motion analysis is involved opens up questions about how the somatic properties of the dance might be made more visible in the data, or might stimulate particular kinds of data visualisations that might then feedback to the dancer more information about the dance. The feedback loop invokes again Merleau-Ponty's views of the phenomenal body and particularly how he divided into the body schema (the body as organism, caused by and in turn causing movement) and the body image (the visualization of the body as an external, represented, object) (Merleau-Ponty, 2002). So, for example, "when a performer is offered visual stimuli from a video loop, the visualized body image drives the body schema" (Polydorou et al 2015, 194). But the intelligence of the corporeal dancing body is not always supported by digital technologies and can enable "a blinded technologization of human movement" (Salazar Sutil 2015, 50). When the tools for motion analysis serve the needs of the dance and not the reverse, we avoid a "dependence on total machine automation" (Salazar Sutil, 2015, 50) and ensures that movement extracted from the body supports an increased attentiveness and consciousness of the dancer's actions, behaviours and relationships with others. However, at the same time, motion analysis tools have led to dance artists being increasingly fascinated with what technologies can offer to their practice and many performance makers are exploring how the physical dancing body can even be absent from the live performance event. These projects have perhaps contributed to a further move away from an ocular-centric choreographic approach, towards a more conceptual, processdriven methodology. Alongside the practice is therefore also a growing discourse that seeks to articulate the particular nature of the human/technology interface in performance, and might contribute thought to how the material body comes into being through bodily expressions in myriad technological environments. 
Movement data for analytic purposes can be captured through different kinds of motion capture technologies and new systems are evolving all the time, often in a move towards making what can be quite sophisticated and complex tools more accessible, usable and affordable. Technologies might include gyroscopes, accelerometers as well as simpler tools such as Kinect. Sophisticated motion capture labs require experts to set up multiple range and depth-sensing cameras. The dancer's movement is captured by means of having sensors (reflective or magnetic markers) attached to various body parts. A common characteristic of motion capture is the extracting movement from a body, and the subsequent abstraction of the body from the physical site of the dance (although performances may involve the dancer moving in reaction to, or in collaboration with, real time motion capture). The disconnection between the live dancer and her data, which can be used in various ways and at different times, can enable the dancer to examine her movement from outside the experience of dancing, and others to also analyse the data sets for myriad purposes. The extraction of data, and data that once processed and turned into a digital avatar that usually appears to carry a clear signature of the dancer and her gestures in the dots, lines and trajectories, can be unsettling or induce an uncanny experience for the dancer. The animation or "digital portrait" (Dils 2002, 94) that emerges is not a mirror image, nor is it necessarily a representation of the dancer so the dancer's sense of self can be disrupted, particularly if glitches enter the animation process.

However, motion capture can produce measurable data, by producing quantitative information about the load on a muscle or joint, etc. as well as qualitative information by representing experience (Schiphorst and Calvert 2015, 243), as well as providing an interesting defamiliarizing experience for the dancer whilst simultaneously making a bridge between 'self and other'. The role of imagery in this process is interesting. If the dancer is repeating a set phrase of movement, image can influence the quality, dynamics and temporal properties, which may reveal more properties of the dance than could otherwise be observed or felt from the 'inside'. Questions arise such as; does the image carry through into the data, or transform through the data? And how might the practicalities of the motion capture process impact on the dancer's habitation of the image? For example, dancers are often required to repeat movement patterns or explorations for the captures to succeed in computational terms. If the dancer is improvising then the process of repetition might disturb the dancer's ability to be 'present', 'in process' and authentic in the improvisation. Even a repeatable or 'set' movement phrase is inherently challenging for dancers who are required to perform a repeated movement for the purposes of capture. Vincs and Barbour recognised this in their project, noting that "for our dancers, performing the same phrases over and over presented the danger of repetitive use injuries, and the very real challenge of finding ways to keep the movement 'alive' in a performative sense in such a repetitive situation. This is, perhaps, one reason that very few large datasets comprising complex contemporary dance movement exist, and this, in and of itself, has been a barrier to the development of motion capture analysis techniques for dance" (Vincs and Barbour, 2014, 66).

\section{Motion analysis in practice}

To examine further the potential partnership between motion analysis and mind images in dance, and how that partnership is informed by or reveals more about somatic practices, I turn now to two examples. The first is the ongoing practice of dance and visual artist Ruth Gibson who working with her partner Bruno Martelli explores how motion capture can reveal more about the imagery that underpins the somatic practice and pedagogy of SRT. Gibson creates moving images and installations, and virtual worlds as locations for enquiry. In some of her work the dancing body, although a source for what is generated, is apparently absent whereas 
in other works such as Summerbranch ${ }^{5}$ (2005) the dancing avatar is more clearly present. A recent enquiry focused on whether and how the materiality of the dancing body could be 'captured' with motion capture technology using Skinner's metaphoric imagery as a source for movement generation ${ }^{6}$. As with many somatic practices, SRT prioritises aspects of movement action that are less visible to cameras or challenge the capture process that uses sensors on the external body. These more elusive aspects include stillness, breath, floor-based movement and partnering work. Capturing what might appear to be 'stillness' reveals the continual activity, hesitations and fluctuations of the body in an apparent state of motionlessness. Gibson then developed these captures into kinetic landscape visualizations to attempt to reveal the metaphoric aspects of the image actions in SRT, such as 'mist' and 'moss'. By attending to the subtleties of human motion the captures unearthed more about the pedagogies and philosophies of SRT and somatic principles at play (Whatley 2015). This work then led to the creation of an application, MocApp, for mobile and tablet screens, using the same captures of experienced SRT practitioners to enable the user to explore human action. The immediacy of the dancing 'stick figures' creates a chance to play with an accessible version of motion capture for experimentation and to create new captures. A related project by Gibson and Martelli, MAN A (2014), focused on kinetic, stylized humanoid forms derived from 3D motion-captured dancers to play with the viewer's proprioception and to elicit kinaesthetic responses akin to the mirror-neuron response creating the potential for embodied empathy with the virtual dancers.

Gibson's projects are not concerned with statistical analyses or measuring/comparing data sets but they demonstrate the synergistic potential of imagery and technology for revealing some of the more intangible aspects of dance practice, and particularly practices that privilege imagination, empathetic communication and movement generation that holistically tune the mind and body. The corporeal dancing body is on one hand rendered into data and then reconstituted in multiple ways, into art works and applications, but each shows how dance is a valuable site for seeing how imagery can source movement that provides access to more insights to the human body in action. As with all projects where the capture is of a human subject, issues of agency and ethics are at stake. In somatic practices, the emphasis is on individual agency, resisting the conditioning models of some more traditional dance techniques, such as classical ballet and some contemporary dance techniques. Dancers working with Gibson are expert SRT practitioners so have a sharp awareness of their own subjectivity but reported finding the motion capture interesting, one acknowledging the transformative experience of being captured, noting:

You need to regularly pause in a particular position (arms outstretched) so that the computer can recalibrate, and actually finding yourself in this place from time to time became quite interesting - like revisiting a familiar place but finding a new resonance each time. I had feared that the outcome of 'capture' would encourage me to become over focused on form rather than the process of the image unfolding but this was not the case, and ..... I think sticking with the process of the image unfolding allowed for a certain clarity of data -

\footnotetext{
${ }^{5}$ The title Summerbranch is a pun as with many of Gibson/Martelli works. It is a play on the title of two choreographic works by Merce Cunningham, Summerspace (1958) and Winterbranch (1964).

${ }^{6}$ The project, 'Capturing Stillness' was the first study to interrogate SRT in the field of motion capture, computer game worlds and interactive virtual environments. It was funded by the Arts and Humanities Research Council and took place at Coventry University (20102013).
} 
that is the forms captured are clearer as a result of not predetermining them.

(cited in Whatley, 2015, 202).

The second example is the WhoLoDance project which has motion analysis at the core of the project ${ }^{7}$ and by generating large datasets of dance movement may well address the problem raised by Vincs and Barber noted earlier. Using machine intelligence tools and methodologies, the aim of WhoLoDance is to apply sequence similarity and clustering methods for analysis of motion captured dance data in order to allow for multiple novel applications in the area of dance analysis and education. Four dance genres are the principal focus for the project because each is to at least some extent codified, so is built around a lexicon of movement actions and sequences that form a basis for the genre's pedagogy: Flamenco, classical ballet, Greek folk dance and contemporary dance. As the project continues and the dance community is more informed of the project and begins user testing the tools as they develop, the aim is to extend the exploration towards the capture of more somatically-informed improvisational dance practices, to test out the premise on which the project is based that the projection of the dancer in relation to the live dancer produces a novel sense of embodiment and a different kind of relationality.

The data that is being generated in WhoLoDance is being analysed in a number of ways, to identify the movement principles and connections between different dance practices, and to support the learning principles that have evolved through the many years of dance teaching within each of the genres. The aim is not to replace the teacher or to provide a virtual proxy for the teacher but rather to enable the dancer and teacher to discover the more hidden properties of the dance genre. The motion capture production is taken through various stages and two pipelines of development. The first, covering both high-end and low-end capture devices will create a blendable motion capture repository, perform data collection and curation, and $3 \mathrm{D}$ position reconstruction for the modelling of the avatar. The second pipeline is concerned with creating the interactive visualization of the virtual bodies that will be used in the installation (polygonal 3D avatars, or real-time visualizations of force fields, vectors of movement and particle point-clouds) that identifies when a physical body is intersecting with a virtual body and feeds back sensory signals to the user.

The ambition is for the WhoLoDance immersive environment to innovate dance teaching and to encourage a greater sense of three-dimensionality by developing a life-size volumetric display that will enable a dancer to literally 'step inside' the dance teacher's body. Whilst other motion training projects have used motion capture to create a virtual dance teaching tool (Chan et al 2011) and have gone some way to collect enough data for evaluating the difference between the learner and teacher, none have yet combined motion capture with virtual reality and hologram technologies to support the teaching of dance with a focus on the qualities of movement and, in particular, the imagery that generates metaphors of motion for the dance learner and teacher. In WholoDance, building a volumetric moving hologram capable of displaying real-time motion capture content will test how dancers respond to virtual environments that feed back information to the dancer about movement 'accuracy' and 'feeling states' as well as the imagery that is the source for their dancing, and may open up new questions about embodiment. The concept is that, by inhabiting a virtual avatar/projection space /holographic projection, the tools will elicit for the dancer a particular

\footnotetext{
${ }^{7}$ WhoLoDance is a Research and Innovation Action funded under the European Union's Horizon 2020 Programme. The project's aim is to develop and apply breakthrough technologies for dance learning; for practitoners, researchers, professionals, dance students and the general public. See http://www.wholodance.eu/.
} 
experience of being 'in' the body, the dancer's own body and the body of another that will be informative, and provide new ways to learn movement and perceive movement from the outside and inside simultaneously.

The main goal from the education perspective is therefore to create methods for learning dance that incorporate novel digital and virtual tools, and which are appropriate for a range of learners providing access to a range of different dance genres through immersive representations of virtual bodies. By giving the student the chance to experiment with different modalities of feedback (audio, visual, audio-visual, verbal, etc.) and also with different virtual environments or different avatars, the project will discover whether it provides interesting opportunities to design adaptive and personalized paths to learning.

\section{Conclusion}

This essay has sketched out the territory of somatic practices and how imagery participates in the dancer's experience of making, performing and teaching dance. Discussion has also focused on motion analysis and outlined some ways in which projects and artists are using motion capture technologies to unearth more of the 'hidden' aspects of dance, whether performed by expert practitioners or enjoyed by those dancing for pleasure and general wellbeing. Reference has also been made to how motion analysis technologies can support the teaching and learning of dance. In this context it is important to recognize that dance is a heterogeneous art form incorporating many styles and techniques. As Vincs and Barbour observe, the "semiotic variability of dance" means that there is "no single 'grammar" of the body [that] can be relied upon to carry the communicative valence of any particular dance movement or practice" $(2014,65)$.

Somatic practices promote a more person-centred approach to movement development than some dance techniques that are more didactic or conditioning. Somatics also encourage embodied thinking and help to tune and train attention, bringing mind and body together. Most dance practices including those with a somatic emphasis recognize and make use of imagery in the training of dancers. Imagery is frequently core to a dancer's perceptual awareness and for enhancing the communication of kinaesthetic data. Imagery can also help dancers make new movement, to notice and break out of movement habits and gain insights to movement qualities. There are multiple ways in which an image can be transformative, "so real that one can become the image" (Skinner, cited in Neuhaus 2010). When brought into the domain of motion capture, image can participate in both the input and output stages, virtualising the sensory, corporeal world of the dancer. Motion analysis also introduces a new perspective, and a new lens on dance, revealing more and sometimes surprising aspects of dance because of the precise detail that the captures can record, as Vincs and Barbour discovered in their integration of PCA analysis of dance (2014). In WhoLoDance, the interrelationship between imagery and technology is core to creating a new sensorial environment and experience for the dancer. Similarly, in Gibson's work, the interrelationship between somatic-informed dance, motion capture and poetic imagery promotes an enhanced embodied perception. The projects discussed here are part of a growing collection of initiatives that are incorporating a variety of motion analysis tools and technologies to support the making and teaching of dance; each exploring the hand in hand relationship between technology, imagery and dance. 


\section{References}

Batson G, Wilson M A (2014) Body and Mind in Motion: Dance and Neuroscience in Conversation. Intellect, Bristol.

Camurri A, Lagerlof I, Volpe G (2003) Recognizing Emotion from Dance Movement: Comparison of Spectator Recognition and Automated Techniques. International Journal of Human-Computer Studies 59: 213-225.

Camurri A, Volpe G, De Poli G, Leman M (2005) Communicating Expressiveness and Affect in Multimodal Interactive Systems. IEEE Multimedia 12 (1): 43-53

Castellano G, Villalba S.D, Camurri A (2007) Recognising Human Emotions from Body Movement and Gesture Dynamics. In: Paiva A, Prada R, Picard R W (eds) $2^{\text {nd }}$ international conference on affective computing and intelligent interaction, Lisbon, September 2007. Lecture notes in computer science. Springer, Heidelberg, p71-82.

Chan J C, Leung H, Tang J K, Komura T (2011) A virtual reality dance training system using motion capture technology. IEEE Transactions on Learning Technologies 4 (2): 187-195.

Dewey J (1958) Experience and nature (Vol. 1). Courier Corporation.

Dils A (2002) The Ghost in the Machine: Merce Cunningham and Bill T. Jones. PAJ: A Journal of Performance and Art 24(1): 92-104.

Emslie M (2009) Skinner Releasing Technique: dancing from within. Journal of Dance and Somatic Practices 2(1): 169-175.

Forsythe W, deLahunta, S (2011) Motion Bank Brochure and Logo Generator. Available via http://motionbank.org/sites/motionbank.org/files/mb brochure.pdf. Accessed 1 Oct 2016.

Foucault M, Martin L H, Gutman H, Hutton P (1988) Technologies of the Self: A Seminar with Michel Foucault. University of Massachusetts Press, Amherst.

Fraleigh S (1996) Dance and the lived body: A descriptive aesthetics. University of Pittsburgh Press, Pittsburgh.

Fraleigh S (2015) Moving Consciously: Somatic Transformations through Dance, Yoga, and Touch. University of Illinois Press, Urbana.

Franklin E (1996) Dance Imagery for Technique and Performance. Human Kinetics Publishers, Champaign, IL.

Hanna T (1980) The Body of Life: Creating New Pathways for Sensory Awareness and Fluid Movement. Healing Arts Press, Rochester, VT.

Harbonnier-Topin N, Simard, H (2015) Somatic Education and Introspective Verbalisation In. Whatley S, Garrett Brown N, Alexander K (eds.) Attending to Movement: Somatic Perspectives on Living in this World. Triarchy, Axminster p 239-250. 
Kapur A, Virji-Babul N, Tzanetakis G, Driessen P F (2005) Gesture-Based Affective Computing on Motion Capture Data. In: Tao J, Tan T, Picard R W (eds) $1^{\text {st }}$ international conference on affective computing and intelligent interaction, Beijing, October 2005. Lecture notes in computer science. Springer, Heidelberg, p1-7.

Kozel S (2007) Closer: Performance, Technologies, Phenomenology. MIT Press, Cambridge MA.

Manen M V (1990) Researching lived experience: Human Science for an Action Sensitive Pedagogy. State University New York Press, New York.

May J, Calvo-Merino B, deLahunta S, McGregor W, Cusack R, Owen A, Veldsman M, Ramponi C, Barnard P (2011) Points in mental space: an interdisciplinary study of imagery in movement creation. Dance Research 29(2): 402-430.

McCarthy R, Blackwell A, Wing A, Hollands K, Barnard P, Nimmo-Smith I, Marcel A (2006) Bodies meet minds: Choreography and cognition. Leonardo 39(5): 475-478.

Merleau-Ponty M (2002) [1962] Phenomenology of perception (trans: Smith C). Routledge, London.

Neuhaus B (2010) The Kinaesthetic Imagination; an interview with Joan Skinner. In Contact Quarterly Online Journal, July 2010. Available via https://community.contactquarterly.com/journal/view/skinner. Accessed 9 October 2013.

Polydorou D, Michailidis, T, Bullock, J. (2015) Communication through Haptic Interaction in Digital Performance. In Salazar Sutil N and Popat S (eds.) Digital Movement: Essays in Motion Technology and Performance. Palgrave Macmillan, Basingstoke, p 189-205.

Salazar Sutil N (2015) Intelligence behind Movement: Laboratories of Biomechanics and the Making of Movement Utopia. In Salazar Sutil N and Popat S (eds.) Digital Movement: Essays in Motion Technology and Performance. Palgrave Macmillan, Basingstoke, p 35-54.

Schiphorst T (2009) The Varieties of User Experience: Bridging Embodied Methodologies form Somatics and Performance to Human Computer Interaction. PhD Dissertation, University of Plymouth.

Schiphorst T, Calvert T (2015) Practising Choreography: Digital Movement as Emergent Praxis. In Salazar Sutil N and Popat S (eds.) Digital Movement: Essays in Motion Technology and Performance. Palgrave Macmillan, Basingstoke, p 239-259.

Sheets-Johnstone M (1966) The Phenomenology of dance. Dance Books, London.

Shippen J, May B (2010) Calculation of muscle loading and joint contact forces during the rock step in Irish dance. Journal of Dance Medicine \& Science 14 (1): 11-18.

Shippen J, May B, Alexander P, Kolk E (2015) Growing Healthier. In Christer K (ed) Proceedings of the $3^{\text {rd }}$ European conference on Design4Health, Sheffield, 2015. 
Shusterman R (1999) Somaesthetics: A disciplinary proposal. The Journal of Aesthetics and Art Criticism 57(3): 299-313.

Shusterman R (2008) Body consciousness: A philosophy of mindfulness and somaesthetics. Cambridge University Press, Cambridge.

Sweigard L E (1974) Human Movement Potential: Its Ideokinetic Facilitation. University Press of America, Lanham, Maryland.

Todd M E (1968) [1937] The Thinking Body: A Study Of The Balancing Forces Of Dynamic Man. Princeton Book Company, Princeton, New Jersey.

Vincs K, Barbour K (2014) Snapshots of complexity: using motion capture and principal component analysis to reconceptualise dance. Digital Creativity 25 (1): 62-78.

Whatley S (2015) Motion Capture and The Dancer: Visuality, Temporality and the Dancing Image. In. Whatley S, Garrett Brown N, Alexander K (eds.) Attending to Movement: Somatic Perspectives on Living in this World. Triarchy, Axminster, p 193-204.

Williamson A (2010) Reflections and theoretical approaches to the study of spiritualities within the field of somatic movement dance education. Journal of Dance and Somatic Practices 2 (1): 35-61.

Williamson A (2016) Reflections on existential phenomenology, spirituality, dance and movement-based somatics. Journal of Dance and Somatic Practices 8 (2) 